\title{
Uterine histology and reproductive cycles in pregnant and non-pregnant opossums, Didelphis virginiana
}

\author{
M. W. Fleming* and J. D. Harder \\ Department of Zoology, The Ohio State University, Columbus, Ohio 43210, U.S.A.
}

\begin{abstract}
Summary. Uteri $(\mathrm{N}=18)$ were collected on Days 3, 7, and 11 of the oestrous cycle or gestation. Reproductive cycles were monitored by vaginal cytology in captive opossums. There was no difference in length of cycles between reproductive states $(29.2 \pm 1.0$ (s.e.m.) days). All uteri on Day 3 or Day 7 were similar in total volume, endometrial width, and glandular abundance. However, on Day 11 endometrial widths were significantly less in pregnant animals and stroma appeared diffuse and flocculent in the non-pregnant uteri. The chorio-vitelline membrane induced no change in the size, conformation, or structure of the uterine epithelium. In some areas, trophoblast cells or their cellular fragments were attached to the epithelium, indicating that the embryonic-maternal relationship might entail adhesion or interdigitation as well as apposition. A mucopolysaccharide layer also characterized this interface of heterologous tissues.
\end{abstract}

\section{Introduction}

The Virginia opossum is the popular example of a prototypic marsupial, closely resembling fossil didelphids (Tyndale-Biscoe, 1973). Recurrent cycles occur monthly from January to July, regardless of the breeding status of the female, if lactational anoestrus is prevented by removal of the young (Hartman, 1923; Jurgelski, 1974). Fertilization occurs in the oviduct, and a mucopolysaccharide layer and a keratinous cortical layer are secreted around the eggs and embryos before arrival in the uterus by Day 3 (McCrady, 1938). Direct embryonic contact with the maternal environment is restricted to the period following Day 7 after loss of the cortical layer. Elaboration of the vascularized chorionic ectoderm over the convoluted surface of the uterine mucosa characterizes this non-invasive type of implantation during the final 3 days of gestation (Hartman, 1923; McCrady, 1938; Hughes, 1974). Litters of 8-12 young are born after a 12.5-day gestation, a period that coincides with the luteal phase of the oestrous cycle in non-pregnant animals. Although several descriptive studies have concluded that the maternal reproductive system was unaltered by the presence of the conceptus based on approximate temporal coincidence of cycles and similarities in uterine morphology (Hartman, 1923, 1928; Morgan, 1946; Reynolds, 1952), no-one has sampled pregnant and non-pregnant opossums systematically to determine the degree of similarity between these two reproductive states. In comparison, an Australian marsupial, the tammar wallaby (Macropus eugenii), has shorter cycles (Merchant, 1979) and altered uterine composition (Renfree, 1972) when pregnant. Our study was designed to compare reproductive cyclicity and uterine histology in pregnant and non-pregnant opossums on equivalent days after oestrus. In addition, the chorio-vitelline membrane and uterine epithelium, the sole interface of heterologous tissues, was examined specifically to determine the nature of the embryonic-maternal association.

* Present address: Department of Animal and Veterinary Sciences, West Virginia University, Morgantown, West Virginia 26506, U.S.A. 


\section{Materials and Methods}

Opossums were maintained in pens $\left(1.0 \mathrm{~m}^{3}\right)$ at the semi-enclosed Opossum Facility of the Department of Zoology, Ohio State University. They were fed a diet of commercial dog food and water. Oestrous cycles were monitored daily by vaginal smears (Hartman, 1923; Jurgelski $\&$ Porter, 1974). Mating (Day 0) was confirmed by finding spermatozoa in the smear and pregnancy by the presence of embryos in utero or of young in the pouch after birth.

Eighteen animals were anaesthetized with ether on Day 3, 7, or 11 of gestation or the oestrous cycle, and a uterus was excised. Uterine volume was estimated by displacement of saline $(9 \mathrm{~g} \mathrm{NaCl} / 1)$; intact uteri were fixed for several days in Bouin's solution and stored in $70 \%$ ethanol. Three segments were taken from the mid-portion of each uterus, one including the broad ligament and two others equidistant around the uterine circumference. Tissues were processed routinely and embedded in paraffin wax, sectioned at $8 \mu \mathrm{m}$ and stained with Harris' haematoxylin and eosin or with alcian blue (pH 2.6) and haematoxylin. From each of the 3 uterine segments, 3 sections, each separated by more than $500 \mu \mathrm{m}$, were measured to obtain a mean endometrial width, i.e. the distance from the myometrium to the lumen. An index of glandular tissue was obtained by photographically enlarging $(\times 40) 3$ of the 9 sections from each animal that were used for measurements of endometrial width. Three transects from the myometrium to the lumen were placed randomly on each print and total glandular tissue crossing each transect was measured to the nearest $1.0 \mathrm{~mm}$.

Effects of reproductive status on uterine parameters were analysed by the Wilcoxon Rank Sum test, and effects amongst days were compared by the Kruskal-Wallis test, Jonckheere Ordered Alternative test, and Dunn's Multiple Comparisons (Hollander \& Wolfe, 1973). Lengths of reproductive cycles were compared by Student's $t$ test (Sokal \& Rohlf, 1969).

\section{Results}

The mean \pm s.e.m. length of cycles i.e. oestrus to oestrus, in which gestation occurred $(29.3 \pm$ 1.8 days, $\mathrm{N}=9)$ was the same as the mean length of nonbreeding cycles $(29.1 \pm 1.2$ days, $\mathrm{N}=$ 15); cycle duration ranged from 22 to 42 days irrespective of breeding status.

Volume of pregnant and non-pregnant uteri were equivalent on each sampling day (Table 1). From Day 3 to Day 11, volumes increased significantly with time $(P<0.01)$. Endometrial

Table 1. Volume, endometrial width, and gland index of opossum uteri on equivalent days of gestation and the oestrous cycle

\begin{tabular}{|c|c|c|c|c|}
\hline & $\begin{array}{l}\text { Reproductive } \\
\text { condition }\end{array}$ & Day 3 & Day 7 & Day 11 \\
\hline \multirow[t]{2}{*}{ Volume (ml) } & Oestrous cycle & $6 \cdot 0 \pm 0$ & $12.7 \pm 0.9$ & $20 \cdot 0 \pm 0$ \\
\hline & Gestation & $6 \cdot 7 \pm 0.7$ & $12 \cdot 7 \pm 1.2$ & $23 \cdot 5 \pm 2.1$ \\
\hline \multirow[t]{2}{*}{ Endometrial width (mm) } & Oestrous cycle & $4.41 \pm 0.80$ & $7 \cdot 13 \pm 0.82$ & $\frac{6 \cdot 50 \pm 0.47^{*}}{(4)}$ \\
\hline & Gestation & $5.74 \pm 0.21$ & $7.42 \pm 0.25$ & $5 \cdot 18 \pm 0.48^{*}$ \\
\hline \multirow[t]{2}{*}{ Uterine gland index $\dagger(\mathrm{mm})$} & Oestrous cycle & $\begin{array}{c}1.0 \pm 0.2 \\
(18)\end{array}$ & $2 \cdot 1 \pm 0 \cdot 1$ & $\begin{array}{c}0.8 \pm 0.1 \\
(27)\end{array}$ \\
\hline & Gestation & $\begin{array}{c}0.8 \pm 0.1 \\
(27)\end{array}$ & $\begin{array}{c}1 \cdot 8 \pm 0.1 \\
(27)\end{array}$ & $\begin{array}{c}1 \cdot 0 \pm 0.1 \\
(36)\end{array}$ \\
\hline
\end{tabular}



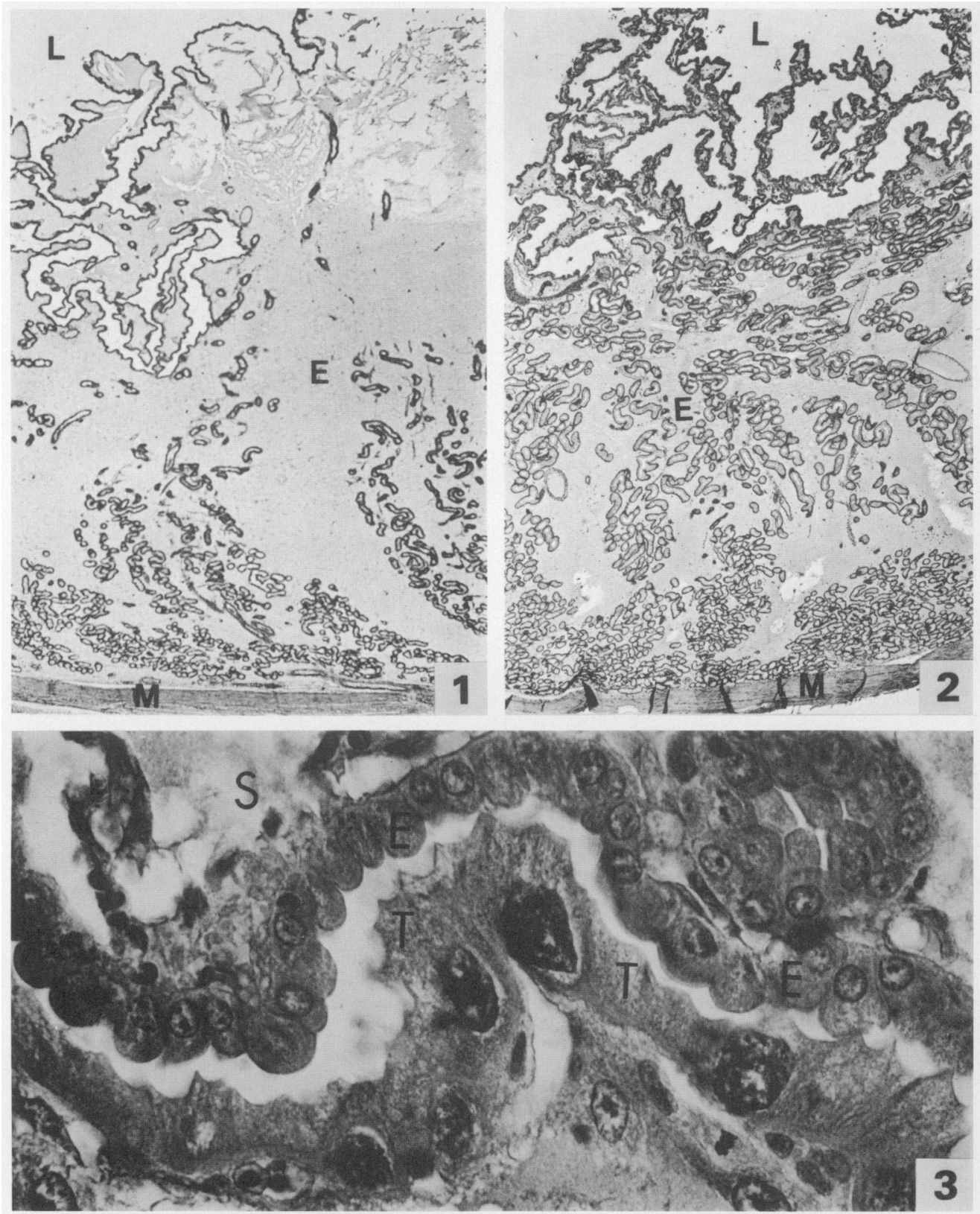

Fig. 1. Cross-section of uterine wall from an opossum on Day 11 of the oestrous cycle, showing the wide endometrium and diffuse and flocculent stroma along the luminal surface. $L=$ lumen; $\mathbf{M}=$ myometrium. Haematoxylin and eosin; $\times 14$.

Fig. 2. Cross-section of uterine wall from an opossum on Day 11 of gestation. Endometrial width was less than in Fig. 1, but the glandular tissue index was similar. $\mathrm{L}=$ lumen; $\mathrm{E}=$ endometrium; $\mathbf{M}=$ myometrium. Haematoxylin and eosin; $\times 14$.

Fig. 3. Apposition of chorio-vitelline membrane and uterine surface epithelium. Trophoblast tissue $(T)$ conformed closely to the shape of individual epithelial cells (E). There was a slight separation of tissues during fixation. $\mathrm{S}=$ stroma. Haematoxylin and eosin; $\times 360$. 
PLATE 2
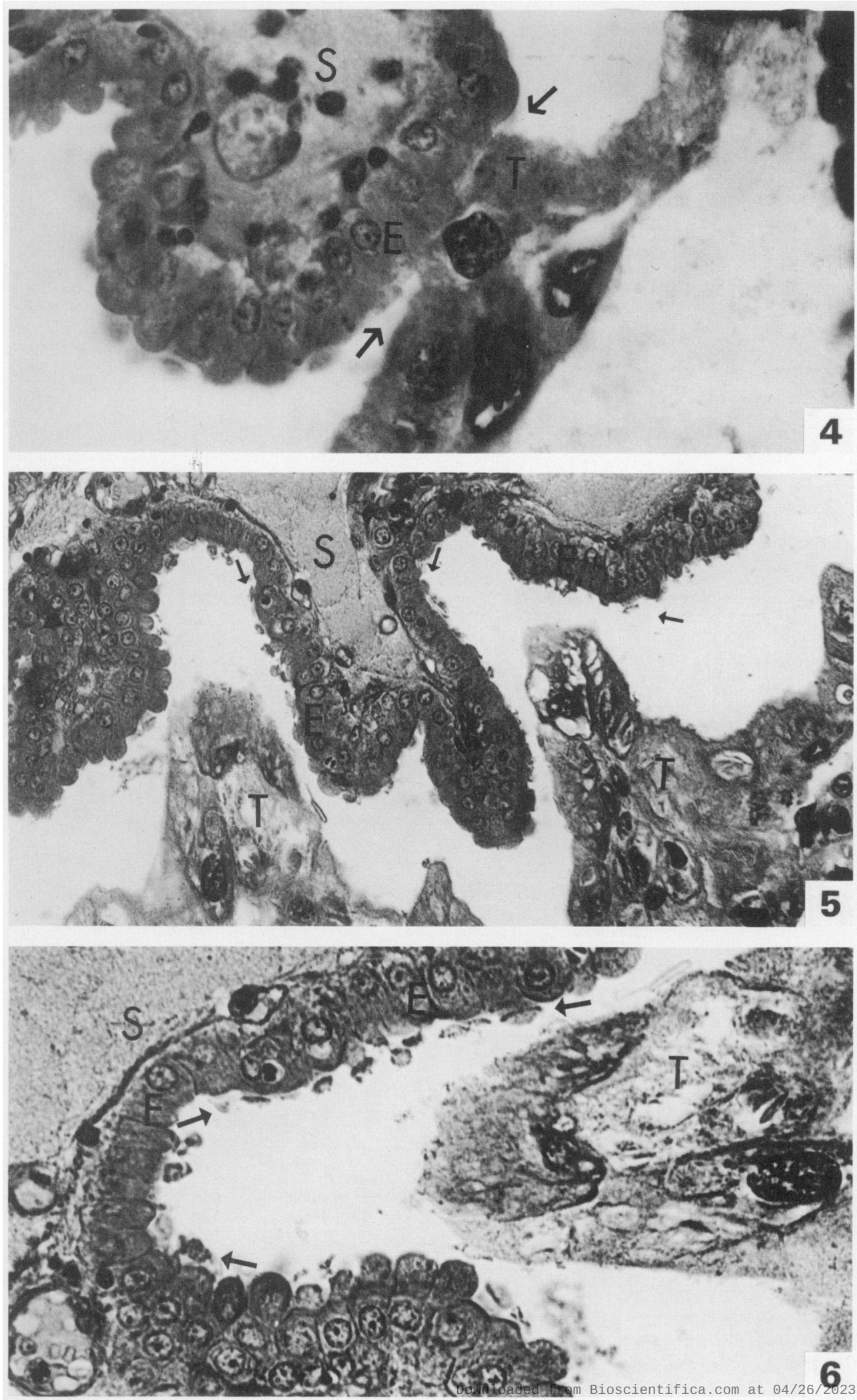
widths were statistically equivalent on Days 3 and 7 but were significantly less in pregnant animals on Day $11(P<0 \cdot 05)$. There were no differences in the uterine gland index on each day (Table 1).

Uteri from pregnant and non-pregnant opossums on Days 3 or 7 were indistinguishable histologically. The presence of embryos had no effect on accumulation of stromal ground substance, glandular proliferation, or epithelial differentiation. However, by Day 11, the uteri of pregnant and non-pregnant animals were distinguishable. In non-pregnant animals, the ground substance subjacent to the surface epithelium was diffuse and flocculent (P1. 1, Fig. 1). By contrast, pregnant uteri had compact stroma, and many sections appeared to contain more glandular epithelium (Pl. 1, Fig. 2). However, the index of glandular tissue (Table 1) did not support this observation $(P>0.05)$. Embryos, chorio-vitelline membranes, and embryonic fluids apparently compressed the endometrium, resulting in dense stroma in the pregnant uterus.

The presence of the chorio-vitelline membrane on Day 11 resulted in no detectable anatomical change in the size, conformation, or structure of the uterine epithelium. The uterine epithelial cells were normally rounded regardless of the juxtaposition of trophoblast on lateral and apical surfaces (Pl. 1, Fig. 3). Despite general separation of these two layers during fixation, trophoblast occasionally maintained contact with the maternal epithelium (Pl. 2, Fig. 4). Furthermore, trophoblast cells frequently ruptured and cell fragments remained attached to the luminal surface of the uterine epithelium (PI. 2, Figs 5 and 6), thus suggesting that adhesion or interdigitation of these tissue layers occurred during late gestation. Trophoblastic cell fragments and the interface of maternal and embryonic tissues were highly alcianophilic, indicating the presence of mucopolysaccharides. Trophoblast cells stained less intensely, and uterine epithelial cells did not stain with the alcian blue on Day 11. Equivalent-day epithelial surfaces from non-pregnant animals were not alcianophilic.

\section{Discussion}

Extensive elaboration of embryonic membranes over the uterine surface increases the surface area for absorption of nutrients and might provide a mechanism for consistent orientation of the embryo (McCrady, 1938). Hughes (1974) classified the non-invasive association of embryonic membranes with the uterine epithelium in didelphids as simple apposition. However, in our opossums, the vascularized chorio-vitelline membrane maintained contact with the maternal tissue, suggesting that cellular adhesion or membrane interdigitation occurred at least 2 days before parturition. In addition, these uterine-embryonic associations appeared homologous with the preimplantation stages of eutherians (Enders, 1976). Adhesion of maternal and embryonic tissues might facilitate transport during late gestation when metabolic requirements are highest.

The uterine gland index declined after mid-gestation, consistent with the pattern of endometrial weights (Renfree, 1975) and widths, whereas the total uterine volume continued to increase, suggesting that the nutritive role of the glandular epithelium decreased during late gestation. Although the uterine glands generally are considered the primary source of

\section{PLATE 2}

Fig. 4. Attachment (between arrows) of trophoblast cells $(T)$ with uterine epithelial cells (E) in the opossum on Day 11 of gestation. $\mathrm{S}=$ stroma. Haematoxylin and eosin; $\times 360$.

Fig. 5. Separation of trophoblast tissue (T) from the uterine surface epithelium (E) in the opossum on Day 11 of gestation. Trophoblast fragments (arrows) remained attached to uterine epithelial apices. $S=$ stroma. Haematoxylin and eosin; $\times 180$.

Fig. 6. Higher magnification of the embryonic-maternal interface to demonstrate the fragmentation of the trophoblastic cells ( $\mathrm{T}$ ) (arrows) due to adhesive or mechanical association with the uterine surface epithelium $(E) . S=$ stroma. Haematoxylin and eosin; $\times 360$. 
embryotrophe (Sharman, 1961), Padykula \& Taylor (1971) described the ultrastructure of the surface epithelium as indicative of a transport function. Therefore, the contribution of glandular epithelium to embryo nutrition might diminish during late gestation and be supplanted by the surface epithelium.

The production of a mucin coat by the trophoblast might contribute to the isolation of the conceptus from the maternal immune response, as suggested during eutherian placentation (Kirby, Billington, Bradbury \& Goldstein, 1964; Currie, Van Doorninck \& Bagshawe, 1968; Amoroso \& Perry, 1975). Jones \& Kemp (1969) proposed that the murine trophoblast prevents lymphocyte attachment by coating its outer surface with a non-adhesive, sialomucin layer. Tyndale-Biscoe (1973) and Lillegraven (1975) suggested that marsupials might not have evolved mechanisms to protect the embryo from allograft rejection and, therefore, are limited to short gestations. This hypothesis was not supported by the findings of Walker \& Tyndale-Biscoe (1978), and our observations also suggest that isolation of the conceptus by mucopolysaccharide complexes might permit an immunological tolerance.

The cumulative evidence from biochemistry (Renfree, 1975; Fleming \& Harder, 1981), histomorphology, and cyclicity supports the hypothesis that gestation in the opossum does not induce unique physiological responses in the mother before parturition occurs.

We thank Patti Raley for technical assistance throughout this study. Funding was provided by The Lalor Foundation and the College of Biological Sciences, The Ohio State University.

\section{References}

Amoroso, E.C. \& Perry, J.S. (1975) The existence during gestation of an immunological buffer zone at the interface between maternal and fetal tissues. Phil. Trans. R. Soc. Lond. B 271, 343-361.

Currie, G.A., Van Doorninck, W. \& Bagshawe, K.D. (1968) Effect of neuraminidase on the immunogenicity of early mouse trophoblast. Nature, Lond. 219, 191-192.

Enders, A.C. (1976) Anatomical aspects of implantation. J. Reprod. Fert., Suppl. 25, 1-15.

Fleming, M.W. \& Harder, J.D. (1981) Effect of pregnancy on uterine constituents of the Virginia opossum. Comp. Biochem. Physiol. 69A (in press).

Hartman, C.G. (1923) The oestrous cycle in the opossum. Am. J. Anat. 32, 353-421.

Hartman, C.G. (1928) The breeding season of the opossum (Didelphis virginiana) and the rate of intra-uterine and postnatal development. J. Morph. 46, 143-215.

Hollander, M. \& Wolfe, D.A. (1973) Nonparametric Statistical Methods. John Wiley, New York.

Hughes, R.L. (1974) Morphological studies on implantation in marsupials. J. Reprod. Fert. 39, 173-186.

Jones, B.M. \& Kemp, R.B. (1969) Self-isolation of the fetal trophoblast. Nature, Lond. 221, 829-831.

Jurgelski, W., Jr (1974) The opossum (Didelphis virginiana Kerr) as a biomedical model. I. Research perspective, husbandry, and laboratory technique. Lab. Anim. Sci. 24, 376-403.

Jurgelski, W., Jr \& Porter, M.E. (1974) The opossum (Didelphis virginiana Kerr) as a biomedical model. III. Breeding the opossum in captivity: methods. Lab. Anim. Sci. 24, 412-425.

Kirby, D.R.S., Billington, W.D., Bradbury, S. \& Goldstein, D. (1964) Antigen barrier of the mouse placenta. Nature, Lond. 204, 548-549.
Lillegraven, J.A. (1975) Biological considerations of the marsupial-placental dichotomy. Evolution 29, 707722.

McCrady, E. (1938) The embryology of the opossum. Am. Anat. Mem. 16, 1-233.

Merchant, J.C. (1979) The effect of pregnancy on the interval between one oestrus and the next in the tammar wallaby, Macropus eugenii. J. Reprod. Fert. $56,459-463$.

Morgan, C.F. (1946) Sexual rhythms in the reproductive tract of the adult female opossum and effects of hormonal treatment. Am. J. Anat. 78, 411-453.

Padykula, H.A. \& Taylor, J.M. (1971) Ultrastructural differentiation of the endometrium of the opossum (Didelphis marsupialis virginiana) during pregnancy. Anat. Rec. 169, 394-395.

Reynolds, H.C. (1952) Studies on reproduction in the opossum (Didelphis virginiana virginiana). Univ. Cal. Publ. Zool. 52, 223-284.

Renfree, M.B. (1972) Influence of the embryo on the marsupial uterus. Nature, Lond. 240, 475-477.

Renfree, M.B. (1975) Uterine proteins in the marsupial, Didelphis marsupialis virginiana, during gestation. $J$. Reprod. Fert. 42, 163-166.

Sharman, G.B. (1961) The embryonic membranes and placentation in five genera of diprotodont marsupials. Proc. zool. Soc. Lond. 137, 197-220.

Sokal, R.R. \& Rohlf, F.J. (1969) Biometry. W. H. Freeman and Co., San Francisco.

Tyndale-Biscoe, C.H. (1973) Life of Marsupials. Elsevier, New York.

Walker, K.Z. \& Tyndale-Biscoe, C.H. (1978) Immunological aspects of gestation in the tammar wallaby, Macropus eugenii. A ust. Sci. 31, 173-182.

Received 2 September 1980 